\title{
Socio-Economic Development and Primary Energy Sources Substitution towards Decarbonization
}

\author{
João Carlos de Oliveira Matias, Tessaleno Campos Devezas \\ ${ }^{1}$ Technological Forecasting and Industrial Management Research Group (TeFIM) Covilhã, Portugal; ${ }^{2}$ Department of Electrome- \\ chanical Engineering, University of Beira Interior, Covilhã, Portugal. \\ Email: matias@ubi.pt; tessalen@ubi.pt
}

Received March $1^{\text {st }}$ 2011; revised April 15 ${ }^{\text {th }}, 2011$; accepted May $10^{\text {th }}, 2011$.

\begin{abstract}
Scanning the last 250 years, we can observe five great technological transformations that happened in the socio-economic development. On the other hand, there is a relationship between the socio-economic development and the substitution process of primary energy sources. Since the industrial revolution, there has been a smooth but growing substitution among primary energy sources. First the switch from wood to coal, then this last one by oil and natural gas. These are non-solid fossils, which leads to a decrease of the carbonic intensity. These substitutions implied some important technological transformations. Bearing in mind a sustainable development of energy systems and using technological forecasting tolls, this study points out to the leadership of the alternative energies among the primary energy sources until 2050-2070. In this sense, even with the predictable overall increase of energy consumption, this study also shows that through the substitution dynamic it is possible not only to reduce the carbonic intensity, but also to reduce the carbonic emission in absolute terms from 2040-2060 on.
\end{abstract}

Keywords: Primary Energy Source Substitution, Technological Transformation, Socio-Economic Development, Sustainable Development, Carbonic Intensity, Decarbonization

\section{Introduction}

Sustainable development can be defined as the development observed in the present without harming the upcoming generations. Energy is easily considered to be an important element of today's society. The energetic necessities are lead by the growth of the population, the economic development and the technologic increase. However, it is know that about a third of the world population still has not any access to any kind of commercial energy. This brings as consequence the inability of satisfying the majority of their basic needs. There is however the moral commitment to make available this commercial energy to about those two million people. This way, even if there were great technological progresses, the energy consumption would continue to increase. Thus, there must be created the necessary conditions to the upcoming generations, becoming essential that the primary preoccupations be focused in terms of basic energetic resources (primary energy sources), i.e., Fossil Fuels (Coal, Oil and Natural Gas), Nuclear Energy (Fission and Fusion) and the Renewable Energies (Biomass, Hydroelectric, Wind, Solar, and Geothermal, among others).

Figure 1 presents the evolution of the primary energy sources market share. It is convenient to enhance two great transitions that were responsible for the structural transformations occurred in the energetic systems. Firstly, the steam engine (associated to coal) and, secondly, the increase of the diversification of the final use technologies and the energy sources diversification. The first transition is related with the first and second technological transformations, while the second transition is, even if not exclusively, linked with the third and fourth technological transformations, standing out the electricity as means of energy transportation and internal combustion engine associate to oil. These transformations appeared intermittently within a period of about a half-century and are linked with waves in the economic activity, and that result from the convergent development on several fields during the past 250 years [1,2]. The first transformation (1770-1800) was linked with the substitution of wood for coal as a primary energy source, with consequences in iron-making, in fuelling the first steam engine, in building the first canals and in mechanizing cotton spinning. The second transformation (1830-1850) was related to 


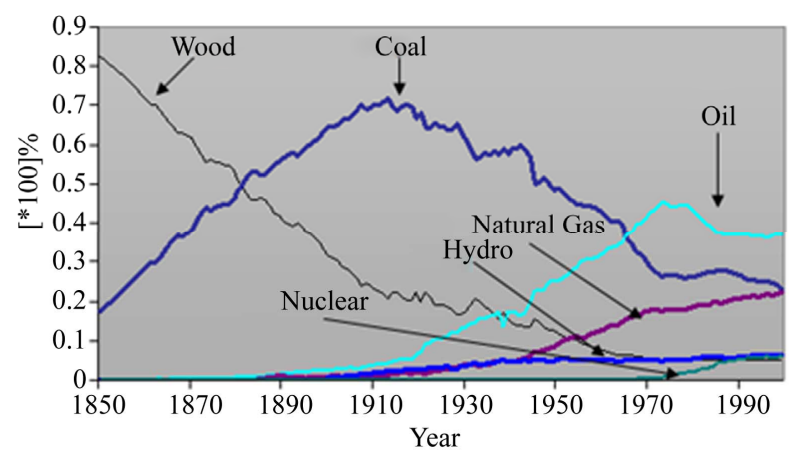

Figure 1. Market share of primary energy sources evolution.

the use of the steam power to the textile industry and to transportation (railways and steam boat). This transformation, along with the first one, is associated to the " $1^{\text {st }}$ Industrial Revolution". The third transformation (1860-1900) was a complex one: it centered itself on steel making and on the mechanization of manufacturing, on illumination, telephones, electrification and on the internal combustion engines. It was also characterized by the beginning of the substitution of coal by oil as primary energy source, being called the " $2^{\text {nd }}$ Industrial Revolution". The fourth transformation (1930-1950) was centered on synthetic materials and electronics. Finally, the fifth beginning around 1980, centers itself on the convergence of computers and telecommunications. This is to say, the first three had a greater influence on industry, being nicknamed as "industrial revolutions". However, the fourth transformation had larger impact on the consumer, given the great amount of new products. The fifth one will influence the industry as much as the consumer, due to the emergence of new products and industrial technologies (also new industries) that will lead this wave.

Figure 1 also shows some points that must be enhanced. From these there can be stood out the following ones:

- The long and gradual substitution among the primary energy sources, such as the substitution of wood (traditional renewable fuel) for fossil fuels.

- The domain of coal during a long period of time, reaching more than two thirds of the consumed primary energy.

- The almost simultaneous introduction of oil and natural gas, this last firstly as a product resultant of the oil production and later as a primary energy source.

- The peak of oil consumption in the seventies, coincident with the oil crisis.

- Finally, some turbulence in the consumption dynamoics of the primary energy sources during the last two decades.

On the other hand, in spite of the increase of carbon emissions to the atmosphere in consequence of the fuels fossil consumption, the carbon emitted by consumed energy unit (carbonic intensity, tC/toe) is decreasing. This is not more than the reflex of the primary energy sources substitution along the last two centuries. First, the substitution of wood (1.25 tC/toe) for coal (1.08 tC/toe), and this last one for NSF [Non Solid Fossils-oil ( $0.84 \mathrm{tC} /$ toe $)$ and, lately, natural gas $(0.64 \mathrm{tC} /$ toe $)]$.

It is noticed, this way, the role of geopolitical dynamics in the transition from wood to coal and from coal to oil (NSF - Non Solid Fossils). It becomes notable the case of the British hegemony in the coal-based regime, while the expansion of oil led to the geopolitical and economic power of the USA, in the post-World War II period, since the $3^{\text {rd }}$ technological transformation was a transition period. In post-World War II period (around twenty five years), the USA dominated in technological terms, having happened there the most important technical progresses. In that period, the technological politics and science and technology investments supported the several researches, mainly of national and space defense interest, facing the "Cold War" against East, principally, against the already extinguished Soviet Union. And in future, how will it be?

Bearing in mind the earlier energy shifts and the important role of geopolitical, commercial and social dynamics in past, probably in future the conventional energy systems will shift in favor of an alternative-based regime, in which the renewable energies and the nuclear energy are included (the short/medium term just the fission). In order to understand the potential for the relative world-rapid diffusion of these new energy technologies it is important to understand the long wave dynamics, having associated regime shifts in the past. Social behaviors changes and environmental issues can lead to a renewable-based regime. But, will they be convergent with geopolitical and commercial interests?

\section{Scenarios}

Making use of two technological forecast tools, namely the logistics curve (quantitative technique) and the Delphi technique (qualitative and judgmental technique), three long-term scenarios [3] were built: an exploratory one, using the substitution logistics (determinists), an Delphi-based indicative one, and another one resulting from combination of the two previous one (hybrid scenario). Notice that, and bearing in mind some presuppositions related with the technologies diffusion time, oil and natural gas are grouped (NSF) in logistic substitution, as like as alternative totality energies (renewable energies without traditional wood and nuclear energy).

For the Delphi-based scenario were selected 180 international energy experts. In $1^{\text {st }}$ round answered 78 panelists, and in the end of the $3^{\text {rd }}$ round the final panel was 
summarized to 68 experts (50\% of Western Europe, $16 \%$ of North America, $13 \%$ of Asia and Oceania, $12 \%$ of South America, 6\% of Eastern Europe and 3\% of Africa).

This article presents only the combined scenario, due to the incorporation of a complementarity between two different techniques. However, notice that one of the reasons for the Delphi technique use (group judgmental technique) was to verify if it is possible to represent the energy systems behavior trough logistic substitution among primary energy sources. In the comparison between exploratory scenario and Delphi-based one it is verified a change dynamics convergence, but there isn't a convergence of "occurrence timing". In other words, the indications of the Delphi survey confirm the dynamics of the logistic substitution, even if considering different time spans, despite of the differences are not very significant [3]. Thus, the hybrid scenario goal is to use the information integration of several sources on different ways in a simple presentation, being grouped the extrapolations results and experts' appreciation. In this way, it was built a scenario that uses a combination between the logistic substitution and the Delphi-based indications. Unlike what it was done for the exploratory scenario (deterministic), there were not chosen identification periods (reference periods for forecasting) for the best data fitting. For each primary energy source, or energy sources groups, it was considered the identification period, which represents the dynamics substitution future, bearing in mind Delphi-based orientations, as well as other kind of indications [3]. Figure 2 shows the substitution between primary energy sources, while Table 1 presents the market share forecasting for the next decades.

However, and in spite of only being explicitly presented the hybrid scenario, through the three scenarios it is possible to point out the following indications [3]:

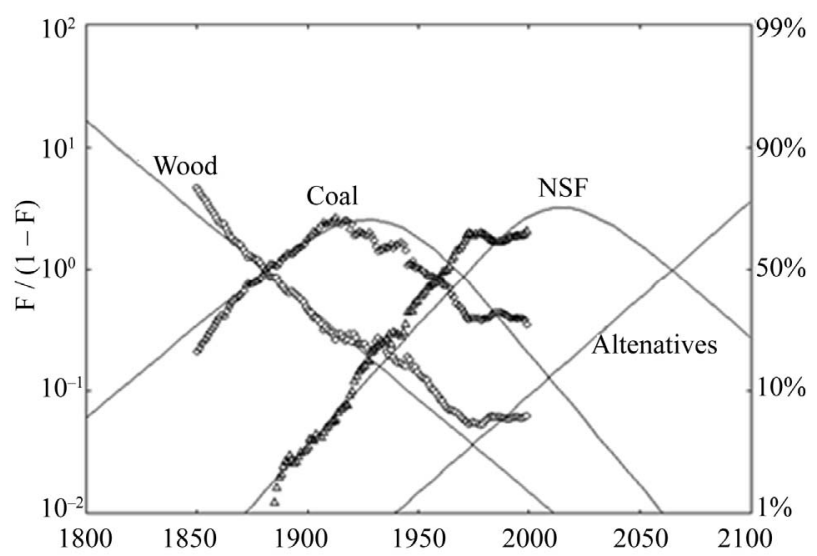

Figure 2. Logistic substitution between primary energy sources (1860-1999) and the market share forecasting for hybrid scenario [3].
Table 1. Market share forecasting for hybrid scenario [3].

\begin{tabular}{cccccccc}
\hline Year Source & 2025 & 2040 & 2045 & 2050 & 2065 & 2075 & 2100 \\
\hline Wood & $<1 \%$ & $<1 \%$ & $<1 \%$ & $<1 \%$ & $<1 \%$ & $<1 \%$ & $<1 \%$ \\
Coal & $6 \%$ & $3 \%$ & $2.5 \%$ & $2 \%$ & $<1 \%$ & $<1 \%$ & $<1 \%$ \\
NSF & $75 \%$ & $68 \%$ & $64.5 \%$ & $61 \%$ & $50 \%$ & $41 \%$ & $22 \%$ \\
Altematives & $19 \%$ & $29 \%$ & $33 \%$ & $37 \%$ & $50 \%$ & $59 \%$ & $78 \%$ \\
\hline
\end{tabular}

- Wood will have its "dusk" (market share $\leq 1 \%$ ), as traditional energy, by 2010-2015.

- Coal will have its “dusk" between 2040 and 2060.

- Among the NSF, natural gas can surpass oil by 2040-2050, but it will be difficultly assumed as main primary energy, if the alternative energies are considered in the totality, being assumed as a NSF "up-grade”, being assumed as a transition fuel.

- NSF can stay in the leadership up until 2050-2070, moment in which they will be surpassed by the group of the alternative energies.

- Nuclear fission will remain as a source of energy, even having the possibility to increase its market share, being very important for the consolidation of the alternative energies, even if not in short terms.

- Nuclear fusion, as commercial energy, will be difficultly available before 2050-2060.

- In short terms, the most effective way to reduce the greenhouse effect is to improve the fossil fuels combustion efficiency.

\section{The Future}

In agreement with the considered and recommended values by the Intergovernmental Panel on Climate Change (IPCC), specifically Wood (1.25 tC/toe), Coal (1.08 tC/toe), Petroleum (0.84 tC/toe) and Natural Gas (0.64 tC/toe) [46], the carbonic intensity evolution is presented in Figure 3, either for the period understood between 1850 and 2000, as for the hybrid scenario. On the other hand, the same figure shows a certain disturbance around 1980 1990. This is not more than a small reduction on the decrease rate, due to the relative increase of coal and wood consumption.

Bearing in mind the carbonic intensity reduction presented by Figure 3 for the hybrid scenario, Figure $\mathbf{4}$ presents the absolute carbon emissions evolution for the three IIASA scenarios, (A - Higher Energy Consumption (41 Gtoe in 2100), B - Medium Energy Consumption (35 Gtoe in 2100), C - Lower Energy Consumption (21 Gtoe in 2100) [7]). For that, the carbonic intensity values calculated for the hybrid scenario were multiplied by the primary energy consumption values presented by each IIASA scenarios. As it can be observed for the three IIASA scenarios, there is an inflection in the 2040-2060 period, corresponding either to the natural gas leadership 


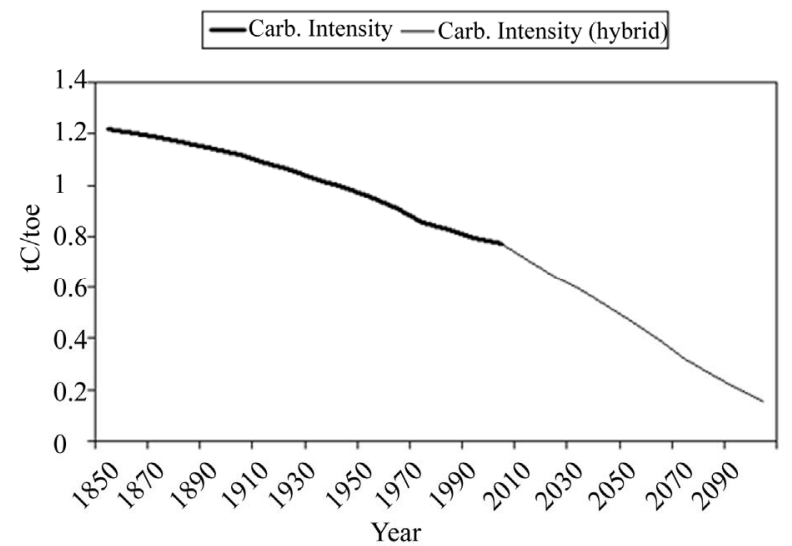

Figure 3. Carbonic Intensity of world energy consumption (tC/toe).

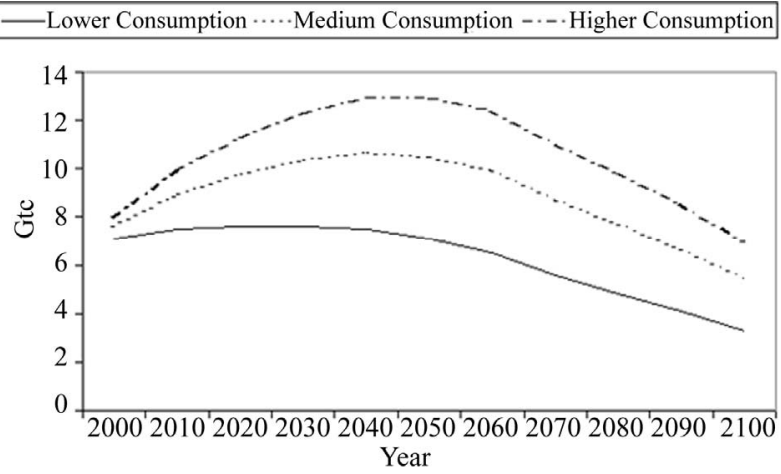

Figure 4. Carbon emissions evolution perspective of the energetic use for the IIASA scenarios A, B, C, in agreement with the carbonic intensity evolution for the hybrid scenario.

among the fossil fuels (2040), as to the coal virtual disappearance (2060). On the other hand, it can also be observed that through the substitution dynamic it is possible not only to reduce the carbonic intensity, but also to reduce the carbonic emission in absolute terms from 2040-2060 on, even with the predictable overall increase of energy consumption. For that, it will contribute the substitution for primary energy sources with smaller carbon emission, such as the natural gas, and for carbon free primary energies sources, such as the alternative energies (the wood in the new designation of solid biomass is not carbon free, but it will be neutral with the proportional forestation to its consumption).

\section{Conclusions}

The substitution for the alternative energies can be slower in case of smaller state intervention than it was in the past. By that time, we will have a key point: on one side, it may exists a less geopolitical interest by state investment in the alternatives, unlike what happened with the British hegemony (coal) and American hegemony (oil). This may not motivate the private investment, due to the great "payback-time" of the alternatives, which have a great initial investment, unlike nowadays fossil fuels. But, on the other hand, it may exists a great bet on alternative energies, due to the need of the resources antidependence.

In a "market economy", the competition is very strong, and as the companies have to satisfy their shareholders, they opt for activities with reduced paybacks. Like this, the energy market liberalization is dangerous for the alternative energies, being doubtful its future $[8,9]$. But the State, on one way or on another, will have to be, just like in the past during the rise of coal and oil and nowadays with the natural gas, the main instigator of the alternative energies. This due to the environmental problems associated to the energy use, besides the elimination of external dependences and the energy technologies importance in the economy. The state support will be the equilibrium point in a liberalized market, guiding and stimulating the investors, even in terms of investments in R\&D. So, private investors by itself won't bet on innovation in alternative technologies. On the other hand, they will have to apply rates and tariffs, due to the externalities associated to each energy source. The current conditions are not attractive for the investors, given the high capitals and long construction periods with returns, if not doubtful, at least slower. But the alternative energies will be an essential factor, besides the combat to the emissions of fossil fuels combustion, in a combat politic to the insecurity of the energy markets, nowadays oil-dependent.

Thus, and bearing mind the nuclear fears, as well as financial factors, the renewable energies group will have an essential role in the two coming structural waves. In this wave $\left(5^{\text {th }}\right)$, on an innovative structural form, and, in the following one, in a structural form of consolidation [10], the alternative energies can reach the leadership as the main primary energy sources during the second half of this century. But, for that, the state intervention will be fundamental, because in the past none of the substitutions were stimulated by the resources depletion, but by technological and social needs, which lead to great structural changes, from which it cannot be dissociated environmental factors. Like this, for the continuity of the substitution process there should be more important economic, geopolitical, environmental and social issues than resources depletion.

Now, we cannot be waiting for the NSF depletion to proceed to the substitution for the renewable energies, because this is going to take place by the end of this century. This paper presents a new way of looking into the future of primary energy sources. A proper substitution dynamics amongst the primary energy sources was de- 
monstrated using an innovative combination between a quantitative technique (logistic substitution), insensible to outward influences, with a judgmental technique (Delphi), capable of forecasting tendencies. Bearing in mind this dynamics it is possible to point out a progressive substitution of the non-solid fossil fuels by the alternative energies.

For the coal-based regime, oil-based regime and, in a certain way, in the beginning of nuclear investigation, there was present geopolitical and world hegemony. On its turn, in the case of the renewable energies, and remaining alternatives, it will be for a question of defense of "external non-dependence", when at this moment most of the NS reserves are in Middle East and Caspian Sea. In this context, during the last years the USA has been having a military and economic position in this region in a "Resources War" perspective. In this context, for the most countries, mainly by a question of defence rather than by a question of dominance in the resources war, the renewable energies constitute the best alternative. However, in order to do so, institutional innovation will be crucial. On the other hand, even if the great radical innovations happen at the more developed countries, other important developments (even if of smaller impact) can happen at countries of smaller development. In other words, the development countries can have an important paper in the research/diffusion of the renewable alternative energies, due to the financial and social problems of nuclear energy, in spite of the possibility of never be despised as an alternative. In this sense, it is believable that we are moving toward alternative energies and, consequently, through the substitution dynamics, it is possible not only to reduce the carbonic intensity, as well as the absolute emission of carbon around 2040-2060.

\section{REFERENCES}

[1] R. U. Ayres, “Technological Transformations and Long Waves - Part I,” Technological Forecasting and Social Change, Vol. 37, No. 1, 1990, pp. 1-37. doi:10.1016/0040-1625(90)90057-3

[2] R. U. Ayres, “Technological Transformations and Long Waves - Part II,” Technological Forecasting and Social Change, Vol. 37, No. 1, 1990, pp. 111-137. doi:10.1016/0040-1625(90)90065-4

[3] J. C. O. Matias, "Scenarios Building for the Primary Energy sources,” Ph.D. Dissertation, University of Beira Interior, Covilhã, 2003.

[4] Intergovernmental Panel on Climate Change (IPCC), “Greenhouse Gas Inventory: Reporting Instructions,” Vol. 1, IPCC/OCDE/IEA, London, 1997.

[5] Intergovernmental Panel on Climate Change (IPCC), "Greenhouse Gas Inventory: Workbook," Vol. 2, IPCC/ OCDE/IEA, London, 1997.

[6] Intergovernmental Panel on Climate Change (IPCC), “Greenhouse Gas Inventory: References Manual,” Vol. 3, IPCC/OCDE/IEA, London, 1997.

[7] L. Schrattenholzer, "Energy Demand and Supply, 1900-2100,” International Institute for Applied Systems Analysis, Laxenburg, 1998.

[8] G. P. Hammond, "Energy, Environment and Sustainable Development: A UK Perspective,” Engineering, Vol. 78, No. 4, 2000, pp. 304-323. doi:10.1205/095758200530826

[9] J. J. Dooley, "Unintended Consequences: Energy R\&D in Deregulated Market,” Energy Policy, Vol. 26, No. 7, pp. 547-555. doi:10.1016/S0301-4215(97)00166-3

[10] T. C. Devezas and J. T. Corredine, "The Biological Determinants of Long Wave Behaviour in Socio-Economic Growth and Development," Technological Forecasting and Social Change, Vol. 68, No. 1, 2001, pp. 1-57. doi:10.1016/S0040-1625(01)00136-6 